\title{
DOSSIÊ
}

\section{Museus, Museologia, Comunicação e Recepção}

\author{
Teresa Scheiner \\ DOI 10.265 I2/museologia.v9iEspecial.35496
}

É com muita satisfação que apresentamos mais um número temático da Revista Museologia \& Interdisciplinaridade, do Programa de Pós-Graduação em Ciência da Informação da Universidade de Brasília - UnB. Trata-se da mais recente produção de uma série que tem-se revelado emblemática para os estudos brasileiros na Área Informação e Comunicação (CAPES), na qual também se situa a Museologia.

Recebemos com alegria o convite para coordenar este número, que escolhemos dedicar ao tema Museus, Museologia, Comunicação, Recepção - tema que nos mobiliza desde sempre e que ganhou novas e inusitadas perspectivas, frente às contingências e exigências deste ano atravessado pela Pandemia do COVID 19. Agradecemos à UnB, aos editores da Revista, Ana Lúcia de Abreu Gomes, Clovis Britto e Monique Magaldi e demais colegas do corpo editorial o voto de confiança, que nos deu oportunidade de apresentar autores que vêm desenvolvendo interessantes reflexões e práticas nesse âmbito.

Os autores convidados têm uma importante trajetória no campo da teoria museológica e da prática especializada em museus; ocupam também um lugar relevante na Academia, como pesquisadores e mestres dedicados à qualificação profissional, formadores de novos museólogos, sensíveis aos rápidos câmbios socioculturais da contemporaneidade e preparados para atuar nos museus do século 21 .

Dentro do espírito interdisciplinar da Revista, convidamos autores com perfis plurais, que em sua atuação profissional já promovem interfaces entre a Museologia e campos afins - Arquitetura e Design, Comunicação, Informação, Marketing Cultural, estudos sobre o Patrimônio e o uso das Tecnologias Digitais em museus. Os dez textos apresentados propiciam um panorama no qual, às teorias e práticas de autores de diferentes estados brasileiros, somam-se o pensamento e a experiência de especialistas da França e de Portugal.

Os treze autores que aqui publicam compartilham suas ideias e experiências sobre aspectos relevantes dessas interfaces. A abordagem teórica se faz presente na questão proposta por Monique Magaldi (Curso de Museologia, UnB, DF) que, na linha dos debates internacionais sobre a definição de Museu, apresenta uma provocação: A UnB é um museu? Seguem-se duas importantes reflexões sobre a Comunicação em museus universitários, tema visto por Letícia Julião (UFMG, MG) como um desafio; e trabalhado na perspectiva dos museus virtuais por Marcus Granato (PPG-PMUS/MAST, RJ), Emanuela Ribeiro (MINTER - PPG-PMUS/UFPE, PE) e Victor Emmanuel Teixeira Mendes Abalada (UFPE, PE). 
Uso da Realidade Aumentada em exposições museológicas:

algumas considerações

As tecnologias digitais são ainda abordadas por quatro autores: Dália Guerreiro, da Universidade de Évora, Portugal, focaliza as relações entre Museologia e as Tecnologias Digitais como dispositivos para a documentação e comunicação dos patrimônios;Alessandra de Oliveira Marçal e Teresa Scheiner (PPG-PMUS, UNIRIO, RJ) comentam o uso da realidade aumentada em exposições museológicas; e Emerson Dionísio (Curso de Museologia, UnB, DF) analisa o museu no Instagram, comentando a ressonância e a visibilidade das práticas museológicas nas redes sociais.

A relação entre exposição e recepção se faz também presente nos textos de Julia Nolasco Leitão Moraes e de Helena Cunha de Uzeda (ambas do PPG-PMUS, UNIRIO, RJ) sobre o horizonte de participação dos públicos na exposição; e sobre a importância das exposições curriculares no ensino de Museologia.Ainda no âmbito das exposições, Jean-Jacques Ezrati, Consultor do Ministério da Cultura de França, comenta sobre a importância do conceito como fundamento para a iluminação em museus.

Finalmente, Rosane Carvalho (MBA em Gestão de Museus, UCAM, RJ) aborda um aspecto muito relevante da recepção: as narrativas e impactos do marketing sobre a imagem pública e a gestão de museus.

Agradecemos aos autores a pronta adesão ao nosso convite e a excelência dos textos apresentados. O cumprimento dos prazos de produção e revisão dos trabalhos permitiu produzir este número especial no curto tempo planejado.

Nesta edição contamos ainda com um grupo de avaliadores do mais alto nível acadêmico, integrado por especialistas em Museologia e Patrimônio: os professores Bruno Melo de Araújo (Escola de Museologia, UFPE), Diana Farjalla Correia Lima (PPG-PMUS e Escola de Museologia, UNIRIO), Josiane Kunzler (Pesquisadora PCl-CNPq/MCTIC), Luisa Maria Gomes de Matos Rocha (PPG-PMUS e Escola de Museologia, UNIRIO), Luiz Carlos Borges (pesquisador titular, MAST e PPG-PMUS), Marcio Ferreira Rangel (pesquisador titular, MAST e PPG-PMUS, UNIRIO), Rosângela Marques de Brito (Instituto de Artes, UFPA) e Simone Weitzel (PPG-Biblioteconomia, UNIRIO) - sendo que esta última também colaborou na normalização das referencias. Agradecemos sinceramente a esses colegas pela disponibilidade na avaliação de seus pares e pela qualidade dos pareceres emitidos.

O resultado do trabalho conjunto desses profissionais pode ser visto agora nesta edição - Número Especial I / 2020 de Museologia \& Interdisciplinaridade. Esperamos que tenha boa receptividade e ressonância entre os leitores e que venha efetivamente a contribuir para as reflexões e os debates no âmbito da Museologia, do Patrimônio, da Informação e da Comunicação. 